\title{
A DEA-TOPSIS approach for ranking credit institutions
}

\author{
Mohammad Ehsani and Abolfazl Danaei*
}

Department of Industrial Management, Semnan branch, Islamic Azad university, Semnan, Iran

\begin{tabular}{|c|c|}
\hline CHRON I C LE & A B S T R A C T \\
\hline $\begin{array}{l}\text { Article history: } \\
\text { Received January 20,2014 } \\
\text { Accepted 5 July 2014 } \\
\text { Available online } \\
\text { August } 112014 \\
\text { Keywords: } \\
\text { Data envelopment analysis } \\
\text { DEA } \\
\text { TOPSIS } \\
\text { Credit institution }\end{array}$ & $\begin{array}{l}\text { Measuring the relative efficiency of financial units plays essential role for making strategic } \\
\text { decisions such as business development, downsizing, etc. This paper presents an empirical } \\
\text { investigation to rank different branches of a credit institution named Samen in city of Semnan, } \\
\text { Iran. The proposed study uses data envelopment analysis (DEA) for measuring the relative } \\
\text { efficiency of } 17 \text { units. The results indicate that five units were efficient and using Technique for } \\
\text { Order of Preference by Similarity to Ideal Solution (TOPSIS), the efficient units are ranked } \\
\text { based on some inputs/outputs. The results of this study indicate that most branches of this } \\
\text { financial unit performed poorly and a restructure in their businesses is necessary. In addition, } \\
\text { the study has provided some evidences that considering employee wage, bank deposit and } \\
\text { administration expenses as inputs for DEA implementation seems to provide better results than } \\
\text { using total assets and equities. }\end{array}$ \\
\hline
\end{tabular}

\section{Introduction}

Calculating the relative efficiency is one of the primary concerns in many financial firms such as insurances, banks, etc. Data envelopment analysis (DEA) has been one of the most popular methods for measuring the relative efficiency of similar units such as bank unites, schools, etc. The benefit of applying DEA is that one may apply the non-financial factors along with the financial numbers to reach a suitable comparison of various units. DEA has been a very popular technique because of simple implementation and interpretation. During the past few decades, there have been many applications of DEA techniques for measuring the relative efficiency of banks (Haslem et al., 1999; Mercan et al., 2003; Fallah et al., 2011). Yang et al. (2010), for instance, proposed an integrated bank performance assessment and management planning by hybrid minimax reference point - DEA approach. Staub et al. (2010) investigated various factors influencing the relative efficiency of Brazilian banks such as expenses and technical efficiencies over the period 2000-2007. They found out that Brazilian banks had suffered from low levels of efficiency compared with European or North

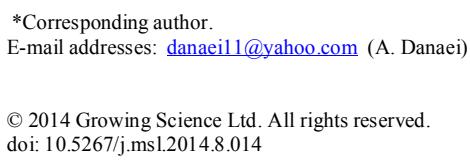


American banks. They also found that state-owned banks were substantially more cost efficient than other foreign units. Nevertheless, they did not report any evidence to claim that the differences in economic efficiency were because of the type of activity and bank size. Avkiran (2010) investigated the relationship between the supper-efficiency estimations and some major key financial ratios for Chinese banking sector. The method provided some opportunity to determine the inefficient units where there was a low correlation between the supper-efficiency and good financial ratios. Lin et al. (2009) executed various DEA models for 117 branches of a certain bank in Taiwan and stated an overall technical efficiency of 54.8 percent for all banks. They also reported that most branches had been relatively inefficient. Thoraneenitiyan and Avkiran (2009) studied DEA and stochastic frontier analsysis (SFA) to conpute the effect of restructuring and country-specific factors on the efficiency of post-crisis east Asian banking systems over the period 1997-2001. They reported that banking system inefficiencies were mainly because of country-specific conditions, such as high interest rates, concentrated markets and economic development. DEA was also applied for banking decisions. For instance, Che et al. (2010) implemented a combination of Fuzzy analytical hierarchy procedure (AHP) and DEA as a decision making facility for making bank loan decisions.

\section{Data envelopment analysis}

The constant return to scale DEA (CCR) was initially proposed by Charnes, et al. $(1978,1994)$ as a mathematical technique for measuring the relative efficiency of decision making units (DMU). One can easily find out how a given DMU works whenever a production function is available. Nevertheless, in several cases obtaining an analytical form for this function may not applicable. Therefore, it is necessary to form a set of production feasibility, which includes some principles such as fixed-scale efficiency, convexity and feasibility as follows,

$$
T_{C}=\left\{(X, Y) \mid X \geq \sum_{j=1}^{n} \lambda_{j} X_{j}, Y \leq \sum_{j=1}^{n} \lambda_{j} Y_{j}, \lambda_{j} \geq 0, j=1, \cdots n\right\},
$$

where $X$ and $Y$ represent the input and output vectors, respectively. The CCR production feasibility set border determines the relative efficiency in which any off-border DMU is considered as inefficient. The CCR model can be detected in two forms of either input or output oriented. The input CCR aims to decrease the maximum input level with a ratio of $\theta$ so that, at least, the same output is generated, i.e.:

$\min \theta$

subject to

$$
\begin{aligned}
& \theta X_{p}-\sum_{j=1}^{n} \lambda_{j} X_{i j} \geq 0, \\
& \sum_{j=1}^{n} \lambda_{j} Y_{r j} \geq Y_{r p}, \\
& \lambda_{j} \geq 0, \quad j=1, \cdots, n .
\end{aligned}
$$

Model (2) is named envelopment form of input CCR where $\theta$ is the relative efficiency of the DMU and it is easy to demonstrate that the optimal value of $\theta, \theta^{*}$, is always between zero and one. In an input oriented DEA model, when the efficiency of a DMU unit, $D M U_{p}$, lines in case of inefficiency, one may change it towards the border to make it efficient. In the case of the output oriented DEA model, the primary objective is to maximize the output level, $\varphi$, by using the same input. The model can be formulated as follows,

$\min \varphi$

subject to

$\sum_{j=1}^{n} \lambda_{j} X_{i j} \leq X_{i p}$ 
$\sum_{j=1}^{n} \lambda_{j} Y_{j} \geq \varphi Y_{i p}$,
$\lambda_{j} \geq 0, \quad j=1, \cdots, n$.

\section{Prioritizing Similar Technologies using TOPSIS Algorithm}

Technique for Order Preference by Similarity to Ideal Situation (TOPSIS) has been a popular technique in the context of multiple-attribute decision making, MADM. An ideal solution is determined as a collection of ideal levels, or ratings, in all attributes considered.

An MADM problem with $m$ alternatives, which are assessed by $n$ attributes may be viewed as a geometric system with $m$ points in the $n$-dimensional space. Hwang and Yoon (1981) developed the TOPSIS based on the idea that the chosen alternative has to maintain the shortest distance from the positive-ideal solution and the longest distance from the negative-ideal solution. TOPSIS is usually applied to rank alternatives through comparing them to the best and the worst solutions. Possibility of incorporating qualitative and quantitative factors is one of the advantages of this method. After detecting more close alternatives to the intended technology based on the calculated scores, they are prioritized with TOPSIS to determine imagined ideal technology, i.e. the most similar technology, based on the shortest distance from the positive ideal alternative and longest distance from the negative ideal alternative. The following summarizes the steps of the algorithm,

1. Normalized decision making matrix (technology alternatives-price factors) is built.

2. Weighted matrix is arranged.

3. The best alternatives among similar technologies are determined.

4. Distance between ideal solution and technology alternatives are arranged.

5. Relative closeness to the ideal solution is measured.

6. Alternatives in an ascending order are sorted.

At the first step, decision matrix are made with numerical values of quantitative indicators -i.e. inherent factors- and utility grades of qualitative indicators using relationships between price factors which was already stated in the previous section. Then normalized matrix are organized by removing dimensions of the matrix arrays through below equation:

$R_{i j}=\frac{X_{i j}}{\sqrt{\sum_{i=1}^{m} X_{i j}^{2}}}, \quad i=1,2, \ldots, m \quad j=1,2, \ldots, n$

where $x_{i j}$ is the array values of decision matrix, and $R_{i j}$ is the normalized values. Since importance of price factors are not equal, a set of weights are used by decision makers to weighting the matrix values. To build this weighted matrix, all arrays of $R$ matrix are multiplied to the column matrix of weights, i.e. ${ }^{W_{j}}$. The normalized weighted matrix is stated as $V$ while we have:

$V_{i j}=W_{j} R_{i j}, \quad i=1,2, \ldots, m \quad j=1,2, \ldots, n$

$\sum_{j=1}^{n} W_{j}=1$

In this step, to determine extreme technology alternatives, two virtual parameters, $T^{+}$and $T^{-}$are defined as below:

$T^{+}=\left\{\left(\operatorname{Max}_{i j} ; j \varepsilon J\right) ;\left(\operatorname{Min}_{i j}^{-} ; j^{-} \varepsilon J^{-}\right) ; i=1,2, . ., m\right\}$

$T^{-}=\left\{\left(\operatorname{MinV}_{i j} ; j \varepsilon J\right) ;\left(\operatorname{Max}_{i j}^{-} ; j^{-} \varepsilon J^{-}\right) ; i=1,2, . ., m\right\}$

where $j=1, \ldots n$ is a set of factors that have positive and $J^{-}$belongs to the set of negative (cost effect) factors. In another word, $T^{+}$is the most similar assumed technology alternative and $T^{-}$is the most distant technology alternative to the intended technology. 
The distance between each alternative and two above mentioned virtual alternatives will be calculated through $n$-dimensions Euclidean distance, i.e.:

$S_{i}^{\max }=\sqrt{\sum_{j=1}^{m}\left(V_{i j}-V_{j \max }\right)^{2}}$,
$S_{i}^{\min }=\sqrt{\sum_{j=1}^{m}\left(V_{i j}-V_{j \min }\right)^{2}}$,

where $S_{i}^{\max }$ is the distance between technology $i$ and the best technology alternative, $T^{+}$; and $S_{i}^{\min }$ is its distance with the worst technology alternative, $T^{-}$. In this step, 'relative closeness' of each $m$ technology alternative would be calculated as follows:

$C_{i}^{*}=\frac{S_{i}^{\min }}{S_{i}^{\max }+S_{i}^{\min }} i=1,2, \ldots, m$

Technology alternatives then are subject to organize according to their relative importance through $C_{i}^{*}$, which is a number between 0 and 1 . Higher $C_{i}^{*}$ indicates that the technology has more priority to be considered as the similar technology to the intended alternative. Thus, the best actual technology alternative are determined after these mentioned steps of TOPSIS algorithm. Now it appears that defining the price would be the next step.

\section{Case study}

Samen credit institution was established as a financial firm in 1997 in Iran and since then there have been over 600 branches in the country. The proposed study of this paper uses DEA method to rank 17 different branches in city of Semnan, Iran. Normally, the implementation of DEA technique yields more than one simple unit and we use TOPSIS technique to rank efficient units. The proposed study considers three inputs including employee wage, bank deposit and administration expenses. In addition, the study considers two outputs including net earnings and loans given to customers. The implementation of the proposed DEA explained earlier yields the relative efficiencies of 17 units summarized in Table 1 as follows,

Table 1

The relative efficiency of 17 units based on the DEA implementation

\begin{tabular}{cccc}
\hline Branch number & Efficiency & Status & Rank \\
\hline 1 & 1 & Efficient & 1 \\
2 & 0.6098 & Inefficient & 15 \\
3 & 0.6757 & Inefficient & 12 \\
4 & 0.7299 & Inefficient & 10 \\
5 & 1 & Efficient & 1 \\
6 & 0.7407 & Inefficient & 9 \\
7 & 0.6711 & Inefficient & 13 \\
8 & 1 & Efficient & 1 \\
9 & 0.8772 & Inefficient & 8 \\
10 & 0.7246 & Inefficient & 11 \\
11 & 0.885 & Inefficient & 7 \\
12 & 0.9174 & Inefficient & 6 \\
13 & 1 & Efficient & 1 \\
14 & 0.6289 & Inefficient & 14 \\
15 & 0.5051 & Inefficient & 17 \\
\end{tabular}

As we can observe from the results of Table 1, six units were relatively efficient and 11 ones were left inefficient. In other words, nearly $65 \%$ of the units are working with inappropriate efficiency 
figures. Next, we have applied TOPSIS method among the six efficient units to find out which units could be considered as the most effective units. In our implementation, we have considered the same inputs/outputs used earlier for DEA method. The results have indicated that unit 5 was the most efficient units followed by unit 1 and unit 13.

\section{Conclusion}

One of the primary concerns on measuring the relative efficiency of similar financial units is to determine important input/output factors when a DEA method is applied. Historically, many researchers have considered total assets and equities as necessary inputs for efficiency estimation. However, the proposed study of this paper has considered employee wage, bank deposit and administration expenses as necessary input parameters. We have presented the results of our investigation for some experts in industry and they have confirmed that the inputs used in this paper represent better factors for efficiency measurement than traditional figures introduced by Mester, (1996), Fu and Heffernan (2007) and Srairi (2010). Based on the results of our survey, it is possible to reduce the number of employees for inefficient units and increase the relative efficiencies, significantly. In addition, we believe it is possible to reduce unnecessary expenses by implementing recent advances technology. The business model has to determine new market opportunities across the country and to introduce new services.

\section{Acknowledgment}

The authors would like to thank the anonymous referees for their comments on the earlier version of this work.

\section{References}

Avkiran, N. K. (2010). Association of DEA super-efficiency estimates with financial ratios: Investingating the case for Chinese banks. Omega, 39(3), 323-334.

Charnes A, Cooper, W. W., \& Rhodes, E. (1978). Measuring the efficiency of decision making units. European Journal of the Operational Research, 2, 429-44.

Charnes A, Cooper W. W., Lewin, A., \& Seiford, L. M. (1994). Data envelopment analysis: theory, methodology and applications. Massachusetts: Kluwer Academic Publishers.

Che, Z. H., Wang, H. S., \& Chuang, Ch-L. (2010). A fuzzy AHP and DEA approach for making bank loan decisions for small and medium enterprises in Taiwan, Expert Systems with Applications, 37(10), 7189-7199.

Fallah, M. Aryanezhad, M.B., Najafi, S.E., \& Shahsavaripour, N. (2011). An empirical study on measuring the relative efficiency using DEA method: A case study of bank industry. Management Science Letters, 1(1), 49-56.

$\mathrm{Fu}, \mathrm{X}$. M., \& Heffernan, S. (2007). Cost X-efficiency in China's banking sector. China Economic Review, 18(1), 35-53.

Haslem, J. A., Scheraga, C. A., \& Bedingfield, J. P. (1999). DEA efficiency profiles of U.S. banks operating internationally. International Review of Economics \& Finance, 8(2), 165-182.

Hwang, C. L., \& Yoon, K. (1981). Multiple Attribute Decision Making Methods and Applications. Springer, Berlin Heidelberg.

Lin, T. T., Lee, Ch-Ch., \& Chiu, T-F. (2009). Application of DEA in analyzing a bank's operating performance. Expert Systems with Applications, 36(5), 8883-8891.

Mercan, M., Reisman, A., Yolalan, R., \& Burak Emel, A. (2003). The effect of scale and mode of ownership on the financial performance of the Turkish banking sector: results of a DEA-based analysis, Socio-Economic Planning Sciences, 37(3), 185-202.

Mester, L. J. (1996). A study of bank efficiency taking into account risk-preferences. Journal of Banking \& Finance, 20(6), 1025-1045. 
Srairi, S. A. (2010). Cost and profit efficiency of conventional and Islamic banks in GCC countries. Journal of Productivity Analysis, 34(1), 45-62.

Staub, R. B., Da Silva e Souza, G. \& Tabak, B. M. (2010). Evolution of bank efficiency in Brazil: A DEA approach. European Journal of Operational Research, 202(1), 204-213.

Thoraneenitiyan, N., \& Avkiran, N. K. (2009). Measuring the impact of restructuring and countryspecific factors on the efficiency of post-crisis East Asian banking systems: Integrating DEA with SFA. Socio-Economic Planning Sciences, 43(4), 240-252.

Yang, J.B., Wong, B.Y.H., Xu, D.L., Liu, X.B. \& Steuer, R.E. (2010). Integrated bank performance assessment and management planning using hybrid minimax reference point - DEA approach. European Journal of Operational Research, 207(3), 1506-1518. 